OPEN ACCESS

Edited by:

Yigang $\mathrm{Xu}$,

Chinese Academy of Sciences, China

Reviewed by:

Huaiwei Ni,

University of Science and Technology

of China, China

Alexandra Yang Yang,

Chinese Academy of Sciences, China

*Correspondence:

Letizia Giulian

letizia.giuliani@unich.it

Specialty section:

This article was submitted to

Petrology,

a section of the journal

Frontiers in Earth Science

Received: 07 February 2020

Accepted: 20 July 2020

Published: 04 August 2020

Citation:

Giuliani L, lezzi G, Hippeli T,

Davis $M$, Elbrecht A, Vetere F, Nazzari M and Mollo S (2020) The Onset and Solidification Path of a Basaltic Melt by in situ Differential Scanning Calorimetry (DSC) and ex

situ Investigations.

Front. Earth Sci. 8:337.

doi: 10.3389/feart.2020.00337

\section{The Onset and Solidification Path of a Basaltic Melt by in situ Differential Scanning Calorimetry (DSC) and ex situ Investigations}

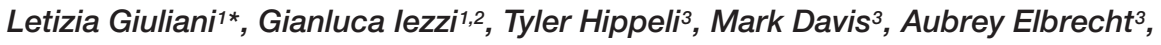 \\ Francesco Vetere ${ }^{4,5}$, Manuela Nazzari ${ }^{2}$ and Silvio Mollo ${ }^{2,6}$ \\ ${ }^{1}$ Dipartimento di Ingegneria e Geologia, Universitá degli Studi di Chieti-Pescara, Chieti, Italy, ${ }^{2}$ Istituto Nazionale di Geofisica \\ e Vulcanologia, Rome, Italy, ${ }^{3}$ SCHOTT North America, Duryea, PA, United States, ${ }^{4}$ Dipartimento di Fisica e Geologia, \\ Universitá degli studi di Perugia, Perugia, Italy, ${ }^{5}$ Institute of Mineralogy, Leibniz Universität Hannover, Hanover, Germany, \\ ${ }^{6}$ Dipartimento di Scienze della Terra, Sapienza Universitá di Roma, Rome, Italy
}

The in situ differential scanning calorimetry (DSC) technique has been applied to investigate the solidification paths of a basaltic liquid. The starting glass was heated up to $1300^{\circ} \mathrm{C}$, kept at this superliquidus temperature for $2 \mathrm{~h}$ and cooled at rates $(\Delta T / \Delta t)$ of $7,60,180,1000$, and $1800^{\circ} \mathrm{C} / \mathrm{h}$, down to 800 and $600^{\circ} \mathrm{C}$. Glass transition temperature $\left(T_{\mathrm{g}}\right)$, crystallization temperature $\left(T_{\mathrm{x}_{-} \mathrm{HR}}\right)$ and melting temperature $\left(T_{\mathrm{m}}\right)$ were measured by in situ DSC spectra on heating. $T_{\mathrm{x}}$ measured along the cooling paths ( $\left.T_{\mathrm{X}} \mathrm{CR}\right)$ shows exothermic peaks that change from a single symmetric shape $\left(7\right.$ and $\left.60^{\circ} \mathrm{C} / \mathrm{h}\right)$ to multi-component patterns $\left(180,1000\right.$, and $\left.1800^{\circ} \mathrm{C} / \mathrm{h}\right)$. The recovered products characterized by field emission gun source of the scanning electron microscopy and electron probe micro-analyzer-wavelength dispersive spectrometers show a phase assemblage of spinel (sp), clinopyroxene (cpx), melilite (mel), plagioclase (plg), and glass. Moreover, crystal size distributions (CSDs) and growth rates ( $G_{\max }$ and $G_{C S D}$ ) were also determined. The crystal content slightly increases from 7 to $1800^{\circ} \mathrm{C} / \mathrm{h}$. Faceted sp are present in all the run products with an amount always $<2$ area\%. Cpx increases from 7 to $1800^{\circ} \mathrm{C} / \mathrm{h}$, changing its texture from almost faceted to dendritic between 60 and $180^{\circ} \mathrm{C} / \mathrm{h}$. The area\% of mel follows an asymmetric Gaussian trend, while plg nucleates only at $7^{\circ} \mathrm{C} / \mathrm{h}$ with a content $<2$ area\%. The coupling of DSC and SEM outcomes indicate that $\mathrm{sp}$ nucleate first, followed by $\mathrm{cpx}$ and mel (and/or plg). The increment of $\Delta T / \Delta t$ causes an increase of the CSD slope $(m)$ and crystal population density per size $\left(n_{0}\right)$, as well as a decrease of the crystal size, for both $\mathrm{cpx}$ and $\mathrm{sp}$. The loglinear CSD segments with different slopes at 7 and $60^{\circ} \mathrm{C} / \mathrm{h}$ suggest multiple nucleation events and crystal growth by coarsening. $G_{\max }$ and $G_{C S D}$ for cpx and sp directly measured on the actual crystallization time by DSC spectra, both increase with the increasing of $\Delta T / \Delta t$. The onset temperature of crystallization $\left(T_{\mathrm{xi}}\right)$ decreases as $\Delta T / \Delta t$ increases, following an exponential trend that defines the uppermost portion of a timetransformation-temperature-like curve. This analytical model allows us to quantitatively model the kinetic crystallization paths of dry basalts.

Keywords: basalt, DSC, in situ crystallization, texture, TTT diagram 


\section{INTRODUCTION}

Basalts are the most erupted and voluminous products on the Earth surface and their solidification behavior has been the most reproduced process by ex situ laboratory experiments. These latter are generally performed starting from liquidus or subliquidus conditions, and quenching the basaltic charges at relative low temperature $(T)$ and/or pressure $(P)$, after different cooling rates $(\Delta T / \Delta t)$ (Cashman, 1993; Lasaga, 1998; Hammer, 2008; Iezzi et al., 2009; Del Gaudio et al., 2010; Vetere et al., 2013, 2015; Mollo and Hammer, 2017) and/or decompression rates $(\Delta P / \Delta t)$ (Hammer, 2008; Applegarth et al., 2013; Fiege et al., 2015; Mollo and Hammer, 2017; Arzilli et al., 2019). Textural and chemical quantifications of the experimental products make it possible to reconstruct the solidification path of a basaltic system. An alternative ex situ approach for investigating nucleation and crystal growth consists of measuring $T$ in basaltic lava flows, sampling the molten portions, and rapidly quenching them in water (Armienti et al., 1994; Burkhard, 2001, 2002, 2003, 2005).

On the other hand, in situ investigations are conducted by different approaches, such as: (1) the direct observation with optical microscopy of crystal nucleation and growth (Sunagawa, 1992; Schiavi et al., 2009; Ni et al., 2014), (2) the use of X-ray and neutron scattering measurements or high-resolution X-ray micro-computed tomography (Baker et al., 2013; Arzilli et al., 2015; Zanatta et al., 2017; Polacci et al., 2018; Tripoli et al., 2019), (3) the measurement of viscosity changes during coolinginduced crystallization of basaltic liquids (Vona et al., 2011; Kolzenburg et al., 2016, 2018a,b, 2020; Tripoli et al., 2019), (4) the measurement of electrical conductivity by impedance spectrometry (Xu et al., 2000; Scarlato et al., 2004; Maumus et al., 2005), and (5) the use of differential scanning calorimetry (DSC) and/or differential thermal analysis (DTA). However, the latter methods are more frequently employed in the field of materials science (Dingwell and Webb, 1990; Shelby, 2005; Zheng et al., 2019) rather than in Earth sciences. Particularly, DSC techniques are the most useful and fastest facility to investigate real-time processes occurring during solidification processes (Lange et al., 1994; Burkhard, 2001; Ray et al., 2005, 2010; Castro et al., 2008; Applegarth et al., 2013; Iezzi et al., 2017; Kolzenburg et al., 2020). DSC allows direct measurements of the heat flux released during an exothermic process (e.g., crystallization), and of the heat flux adsorbed during the endothermic ones (e.g., glass transition and melting). As a result, the DSC spectra ( $T$ vs $\mu \mathrm{V} / \mathrm{mg}$ ) resulting from calorimetric solidification experiments show troughs when the glass transitions $\left(T_{\mathrm{g}}\right)$ and melting $\left(T_{\mathrm{m}}\right)$ occur, and peaks when crystal nucleation and growth start $\left(T_{\mathrm{x}}\right)$. However, despite its effectiveness, in situ DSC techniques have rarely been used to investigate melting and crystallization processes in basaltic materials (Onorato et al., 1980; Lange et al., 1994; Burkhard, 2001; Ray et al., 2005, 2010; Castro et al., 2008; Applegarth et al., 2013; Iezzi et al., 2017), mainly upon heating (glasses) and to a lesser extent on cooling (melts).

Previous in situ investigations conducted on chemically complex (natural) silicate melts (Schiavi et al., 2009; Ni et al., 2014; Kolzenburg et al., 2018a,b) simulated only limited cooling rate $(\Delta T / \Delta t)$ conditions and/or restricted thermal ranges of cooling $\left(\Delta T_{c}\right)$. However, natural basaltic liquids solidify under highly variable $\Delta T / \Delta t$ from liquidus or sub-liquidus regions down to solidus temperatures which are still poorly explored (cf. Giuliani et al., 2020a,b) and are important to correctly interpret the thermal interval of crystallization $(\Delta T c)$.

Most of the early experiments on the onset of melt crystallization as a function of cooling rate were not analyzed with scanning electron microscopy (SEM) and/or electron microprobe (EPMA) (Klein et al., 1975; Uhlmann et al., 1975, 1981, 1979; Onorato and Uhlmann, 1976; Onorato et al., 1980), thus preventing quantitative textural and chemical determinations. The only available time-temperature-transformation (TTT) and continuous cooling (CCT) diagrams for basaltic liquids still refer to these pioneering works (Uhlmann et al., 1981; Weinberg and Zanotto, 1989), albeit more recent data have been also reported in literature (Ray et al., 2005; Vetere et al., 2013; Rogez et al., 2017).

In this study, we have combined in situ DSC investigations (on heating and especially on cooling) with ex situ textural analysis conducted on a basaltic melt cooled from liquidus to solidus conditions using a broad range of rates of 7, 60, 180, 1000, and $1800^{\circ} \mathrm{C} / \mathrm{h}$. The SEM analysis on the obtained run products allows the quantification of crystal content (area\%), crystals per area (\#/A), crystal size distributions (CSDs), and the growth rates of clinopyroxene (cpx) and spinel (sp). The chemical composition of phases was obtained by EPMA-WDS. The in situ measurement of the thermal crystallization onset $\left(T_{\mathrm{xi}}\right)$ leads to analytically model the crystallization paths of basalts, at thermal conditions comparable to those observed for naturally cooling magmas (Vetere et al., 2013, 2015; Giuliani et al., 2020b).

\section{DIFFERENTIAL SCANNING CALORIMETRY}

Differential scanning calorimetry is the most common method to investigate the kinetics of solidification, particularly referred to the glass stability (GS) and glass-forming ability (GFA) behaviors (Zheng et al., 2019). Although this, DSC is not so used in Earth Sciences, except few investigations (Onorato et al., 1980; Dingwell and Webb, 1990; Burkhard, 2001; Ray et al., 2005, 2010; Castro et al., 2008; Applegarth et al., 2013; Iezzi et al., 2017; Kolzenburg et al., 2020).

DSC technique allows to quantitatively determine in situ the thermodynamic changes occurring during the transformation of a liquid into a solid (cooling) and vice versa (heating). These changes are recorded in terms of differential heat flux, measured as $\mathrm{DSC} /(\mu \mathrm{V} / \mathrm{mg})$, between the analyzed sample and a reference standard (Shelby, 2005). In a typical DSC spectrum, the recorded $\mathrm{DSC} /(\mu \mathrm{V} / \mathrm{mg})$ is related to $T\left({ }^{\circ} \mathrm{C}\right)$, as shown in Figures 1, 2A and Supplementary Figure $\mathbf{S} 1$. The endothermic and exothermic peaks result respectively from the heat absorption and release accompanying phase transformations. When the sample reaches the melting point, the recorded heat flux is lower than that of the standard, resulting in the appearance of an endothermic peak that corresponds to the melting temperature $\left(T_{\mathrm{m}}\right)$. A similar peak occurs when the sample passes through the glass transition region $\left(T_{\mathrm{g}}\right)$. Contrarily, during the crystallization of the sample, 


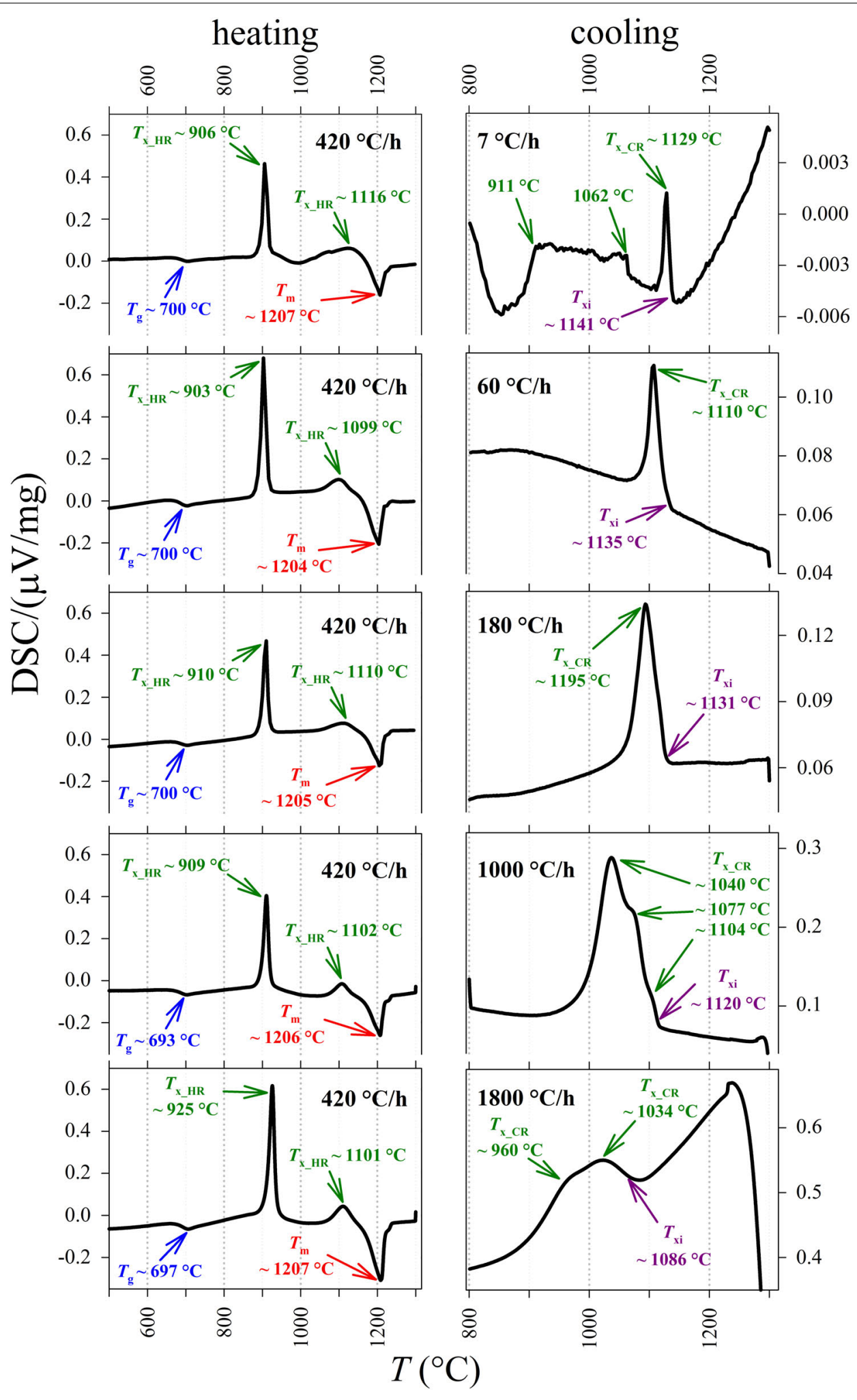

FIGURE 1 | DSC spectra for the basaltic melt, relating the DSC signal based on the differential heat flux (DSC/ $\mu \mathrm{V} / \mathrm{mg}))$ and $T\left({ }^{\circ} \mathrm{C}\right)$. On the left: heating treatment from ambient temperature to $1300^{\circ} \mathrm{C}$ at $420^{\circ} \mathrm{C} / \mathrm{h}$. On the right and from top to bottom: cooling rate paths at $7,60,180,1000$, and $1800^{\circ} \mathrm{C} / \mathrm{h}$, respectively. Glass transition temperature $\left(T_{\mathrm{g}}\right)$, crystallization temperature $\left(T_{\mathrm{x}} \mathrm{HR}\right)$ and melting temperature $\left(T_{\mathrm{m}}\right)$ were measured by in situ DSC spectra acquired on heating. $T_{\mathrm{x}}$ was also measured along the cooling path of the melt $\left(T_{X_{-}} C_{R}\right)$. The temperature of the onset of crystallization $\left(T_{x i}\right)$ has been computed at $10 \%$ of the maximum intensity of the crystallization peaks. 

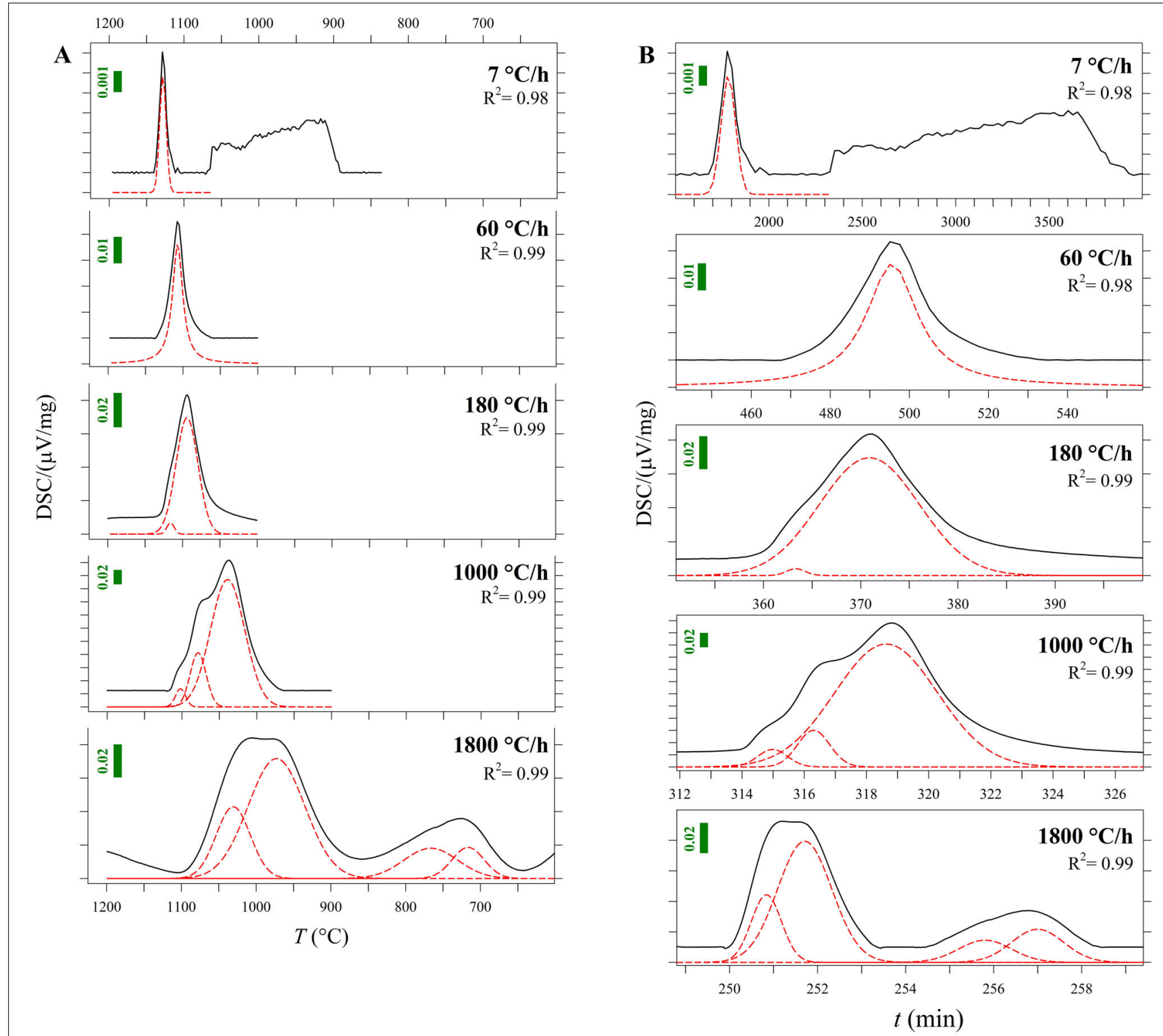

FIGURE 2 | (A) Zoom-in of DSC curves as a function of temperature (T) from Figure 1 and Supplementary Figures S1A-E (blue lines). The fitted components of these peaks are plotted in red and listed in Table 3. Vertical bars show the Y-axis scale. (B) DSC curves as a function of time ( $t$ ). The fitted components of these peaks are plotted in red and listed in Table 3. Vertical bars show the Y-axis scale.

the heat flux from the sample is higher than that from the standard, causing the appearance of an exothermic peak on the DSC spectrum at the crystallization temperature $\left(T_{\mathrm{x}}\right)$.

In this work, $T_{\mathrm{m}}$ and $T_{\mathrm{g}}$ have been identified during the heating processes, while $T_{\mathrm{x}}$ has been measured both on heating $\left(T_{\mathrm{x}_{-} \mathrm{HR}}\right)$ and along the cooling path $\left(T_{\mathrm{X}_{-} \mathrm{CR}}\right)$.

\section{EXPERIMENTS AND STARTING MATERIAL}

A tholeiitic basalt from Iceland $\left(\mathrm{B}_{100}\right)$ was used to produce a homogeneous starting glass, following the procedure described in Vetere et al. (2013, 2015). This natural rock is an USGS-international standard known as BIR-1a, which starting composition (wt.\%) is: $\mathrm{SiO}_{2}=48.0 ; \mathrm{TiO}_{2}=1.0 ; \mathrm{Al}_{2} \mathrm{O}_{3}=15.6$; $\mathrm{FeO}=10.2 ; \mathrm{MnO}=0.2 ; \mathrm{MgO}=9.4 ; \mathrm{CaO}=13.2 ; \mathrm{Na}_{2} \mathrm{O}=1.8 ;$ $\mathrm{K}_{2} \mathrm{O}=0.0 ; \mathrm{P}_{2} \mathrm{O}_{5}=0.1 ; \mathrm{H}_{2} \mathrm{O}=0.005$.

The $\mathrm{B}_{100}$ starting glass was powdered and melted twice at $1600^{\circ} \mathrm{C}$ for $4 \mathrm{~h}$ (ambient $P$ and $f \mathrm{O}_{2}$ of air) and, then, rapidly quenched on a metal plate. For each experiment, several mmsized $\mathrm{B}_{100}$ glass beads were inserted in cylindrical Pt-crucible with a diameter of $6 \mathrm{~mm}$ and a length of $4.3 \mathrm{~mm}$. The Ptcharge was lodged in a DSC (Netzsch STA 449F1) installed at the laboratory of SCHOTT Research \& Development - North America in Duryea (Pennsylvania, United States) and heated at 
a rate of $420^{\circ} \mathrm{C} / \mathrm{h}$ from room temperature to the superliquidus conditions of $1300^{\circ} \mathrm{C}$ (ambient $P$ and $f \mathrm{O}_{2}$ of air; see Table 1). The Pt-charges were kept at $1300^{\circ} \mathrm{C}$ for $2 \mathrm{~h}$ and then cooled at rates of $7,60,180,1000$, and $1800^{\circ} \mathrm{C} / \mathrm{h}$ down to 800 and $600^{\circ} \mathrm{C}$ (Table 1). The solidification path (heating rate, dwell time, and $\Delta T c)$ used in this study are comparable with those adopted by Vetere et al. $(2013,2015)$, that applied cooling rates of $1,7,60$, 180,1800 and $9000^{\circ} \mathrm{C} / \mathrm{h}$. The DSC spectra were fitted with a linear background, while the exothermic and endothermic peaks are reproduced using pseudo-Voigt components, such to reproduce the observed spectra and to minimize the difference between measured and calculated DSC patterns.

The recovered run products were mounted in epoxy resin and polished to expose a flat surface. Photomicrographs were collected in the back-scattered electron (BSE) mode, using a field emission gun source of the scanning electron microscopy (FEG-SEM) Jeol 6500F (JEOL, Ltd., Tokyo, Japan). The chemical attributes of phases were determined by an electron probe microanalyzer (EPMA) Jeol JXA-8200 equipped with five wavelength dispersive spectrometers (WDS). Analyses were performed under vacuum using an electron beam of $5 \mu \mathrm{m}$, an accelerating voltage of $15 \mathrm{kV}$, and an electric current of $7.5 \mathrm{nA}$. The following standards were adopted: Albite $(\mathrm{Na}, \mathrm{Si}$, and $\mathrm{Al})$, Forsterite $(\mathrm{Mg})$, Orthoclase $(\mathrm{K})$, Augite (Fe), Rutile (Ti), Apatite (Ca and $\mathrm{P})$ and Chromite $(\mathrm{Cr})$. Sodium and potassium were analyzed first, to limit their possible migration. Both FEG-SEM and EPMA are installed at the HPHT Laboratory of Experimental Volcanology and Geophysics of the Instituto Nazionale di Geofisica e Vulcanologia (INGV) in Rome, Italy.

The textural features of the run products have been quantified by image analysis on several BSE-SEM micro-photos with magnifications from 100 to $5000 \times$ (Table 1). The image analysis processing is reported in detail in several previous studies (Lanzafame et al., 2013, 2017; Vetere et al., 2013, 2015; Giuliani et al., 2020b); the quantitative textural data are available in the supplementary excel-spreadsheet. The type, size, and distribution of each crystalline phase were measured, plus the CSD analysis. Crystal size distribution curves were calculated using the CSDcorrections software (Higgins, 2006; Giuliani et al., 2020b).

\section{RESULTS}

\section{DSC Spectra}

Differential scanning calorimetry spectra of all the experimental charges are displayed in Figure 1; more details and relative thermal paths are reported in Supplementary Figures S1AE. At the heating rate of $420^{\circ} \mathrm{C} / \mathrm{h}$ it is found (i) a first endothermic peak corresponding to $T_{\mathrm{g}}$, (ii) two exothermic peaks corresponding to $T_{\mathrm{x}_{-} \mathrm{HR}}$, and (iii) a further intense endothermic peak related to the attainment of $T_{\mathrm{m}} . T_{\mathrm{g}}$ occurs between 693 and $700^{\circ} \mathrm{C}$, averaging $698 \pm 3^{\circ} \mathrm{C}$ [i.e., $42^{\circ} \mathrm{C}$ above the value of $651^{\circ} \mathrm{C}$ computed by Vetere et al. (2015); Table 2]. The first and second peaks of $T_{\mathrm{X} \_ \text {HR }}$ are centered between 903 and $925^{\circ} \mathrm{C}$ (average of $911 \pm 9^{\circ} \mathrm{C}$ ) and between 1099 and $1116^{\circ} \mathrm{C}$ (average of $1104 \pm 7^{\circ} \mathrm{C}$ ), respectively (Table 2 and Figure 1). The peaks of $T_{\mathrm{m}}$ vary slightly between 1204 and $1207^{\circ} \mathrm{C}$, averaging $1205 \pm 1^{\circ} \mathrm{C}$ [i.e., $20-25^{\circ} \mathrm{C}$ and just below the value of $1233^{\circ} \mathrm{C}$ computed by Vetere et al. (2015); Table 2 and Figure 1].

At superliquidus conditions, there are no thermal peaks because the melt is fully relaxed (Supplementary Figures S1AE), whilst one or more exothermic peaks occur at different temperatures as a function of the cooling paths (Figure $\mathbf{1}$ and Supplementary Figures S1A-E). At $\Delta T / \Delta t$ of $7^{\circ} \mathrm{C} / \mathrm{h}$, the DSC spectrum shows a first exothermic peak centered at $1129^{\circ} \mathrm{C}$, followed by broadband composed of several exothermic peaks between 1062 and $911^{\circ} \mathrm{C}$ (Figure 1). At $\Delta T / \Delta t$ of $60^{\circ} \mathrm{C} / \mathrm{h}$, a unique asymmetric exothermic peak occurs at $1110^{\circ} \mathrm{C}$ (Figure 1). At $\Delta T / \Delta t$ of $180^{\circ} \mathrm{C}$, a slightly asymmetric peak is centered at ca. $1095^{\circ} \mathrm{C}$ (Figure 1), whilst at 1000 and $1800^{\circ} \mathrm{C} / \mathrm{h}$ the corresponding exothermic peaks are broad and composed of several components, which maximum values are in the thermal ranges of $1104-1040^{\circ} \mathrm{C}$ and $1034-960^{\circ} \mathrm{C}$, respectively (Figure 1).

To accurately quantify the onset temperature of nucleation under the effect of cooling rate, the first peaks were fitted, as displayed in Figure 2A. DSC patterns as a function of time are reported in Figure 2B. On cooling, The high- $T$ peaks occurring at $\Delta T / \Delta t$ of 7 and $60^{\circ} \mathrm{C}$ can be fitted with a single symmetric component, whereas those at $\Delta T / \Delta t$ of 180,1000 and $1800^{\circ} \mathrm{C} / \mathrm{h}$ are fitted with two, three and four components, respectively (Figure 2A); Table 2 lists these temperatures. The temperature of the onset of crystallization $\left(T_{\mathrm{xi}}\right)$ has been determined by considering the temperature value at $10 \%$ of the maximum intensity of the first peak on cooling and related to crystallization. $T_{\text {xi }}$ progressively shifts toward lower values as $\Delta T / \Delta t$ increases (Figure 1 and Table 2). In particular, increasing the $\Delta T / \Delta t$ from 7 to $1800^{\circ} \mathrm{C} / \mathrm{h}$, decreases the value of $T_{\mathrm{xi}}$ from 1141 to $1086^{\circ} \mathrm{C}$, as reported in Table 2 . The difference between averaged $T_{\mathrm{m}}$ and $T_{\mathrm{xi}}$ corresponds to the degree of undercooling $\left(\Delta T_{i}\right)$, listed in Table 2. Table 3 lists the quantitative attributes of all the fitted components from the DSC spectra.

TABLE 1 | Thermal paths used for in situ DSC experiments and BS-SEM microphotographs used for image analysis.

\begin{tabular}{|c|c|c|c|c|c|c|c|c|}
\hline $\begin{array}{l}\text { Experimental } \\
\text { label }\end{array}$ & $\begin{array}{c}\text { Heating } \\
\text { rate }\left({ }^{\circ} \mathrm{C} / \mathrm{h}\right)\end{array}$ & $T_{i}\left({ }^{\circ} \mathrm{C}\right)$ & Dwell time (h) & $\Delta T / \Delta t\left({ }^{\circ} \mathrm{C} / \mathrm{h}\right)$ & $T_{f}\left({ }^{\circ} \mathrm{C}\right)$ & $\begin{array}{l}\text { Experimental } \\
\text { time (h) }\end{array}$ & $\begin{array}{l}\text { \# Microphotographs for } \\
\text { image analysis }\end{array}$ & Image magnification \\
\hline DSC-7 & 420 & 1300 & 2 & 7 & 800 & 78.7 & 5 & $100 \div 350 \times$ \\
\hline DSC-60 & & & & 60 & & 14.6 & 3 & $200 \div 250 x$ \\
\hline DSC-180 & & & & 180 & & 10.0 & 5 & $200 \div 500 x$ \\
\hline DSC-1000 & & & & 1000 & & 6.6 & 4 & $500 \div 1000 x$ \\
\hline DSC-1800 & & & & 1800 & 600 & 5.7 & 5 & $1000 x$ \\
\hline
\end{tabular}


TABLE $2 \mid T_{\text {g_HR }}, T_{x_{-} H R}, T_{m}, T_{x_{-} C R}, T_{\text {xi }}$, and $\Delta T_{i}$ determined by DSC experiments.

\begin{tabular}{|c|c|c|c|c|c|c|c|c|c|c|c|}
\hline Calculated $T_{\mathrm{g}}$ & $T_{\mathrm{g}-H R}$ & Average $T_{\mathrm{g} \_H R}$ & $T_{\mathrm{x} \_H R}$ & Average $T_{\mathrm{X} \_H R}$ & $T_{\mathrm{m}}$ & Average $T_{\mathrm{m}}$ & Calculated $T_{\mathrm{m}}$ & $\Delta T / \Delta t$ & $T_{\mathrm{X} \_C R}$ & $T_{\mathrm{xi}}$ & $\Delta T_{i}$ \\
\hline \multirow[t]{5}{*}{651} & 700 & $698( \pm 3)$ & $906-1116$ & $\begin{array}{c}911( \pm 9)- \\
1104( \pm 7)\end{array}$ & 1207 & $1206( \pm 1)$ & 1233 & 7 & $1129-1062 / 911$ & 1141 & 65 \\
\hline & 700 & & 903-1099 & & 1204 & & & 60 & 1110 & 1135 & 71 \\
\hline & 700 & & $910-1100$ & & 1205 & & & 180 & 1095 & 1131 & 75 \\
\hline & 693 & & $909-1102$ & & 1206 & & & 1000 & 1104-1040-1077 & 1120 & 86 \\
\hline & 697 & & $925-1101$ & & 1207 & & & 1800 & 1034-960 & 1086 & 120 \\
\hline
\end{tabular}

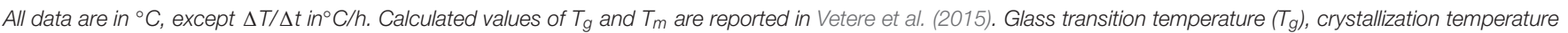

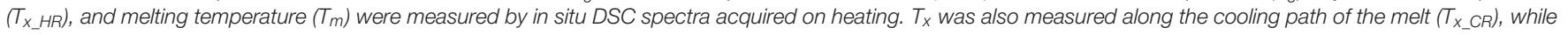
$T_{x}$ has been measured at $10 \%$ of the maximum intensity of the first crystallization peak. The degree of undercooling ( $\left.\Delta T_{i}\right)$ was calculated as $T_{m}$ average $-T_{x i}$.

TABLE 3 | Data from DSC spectra and calculated crystallization time.

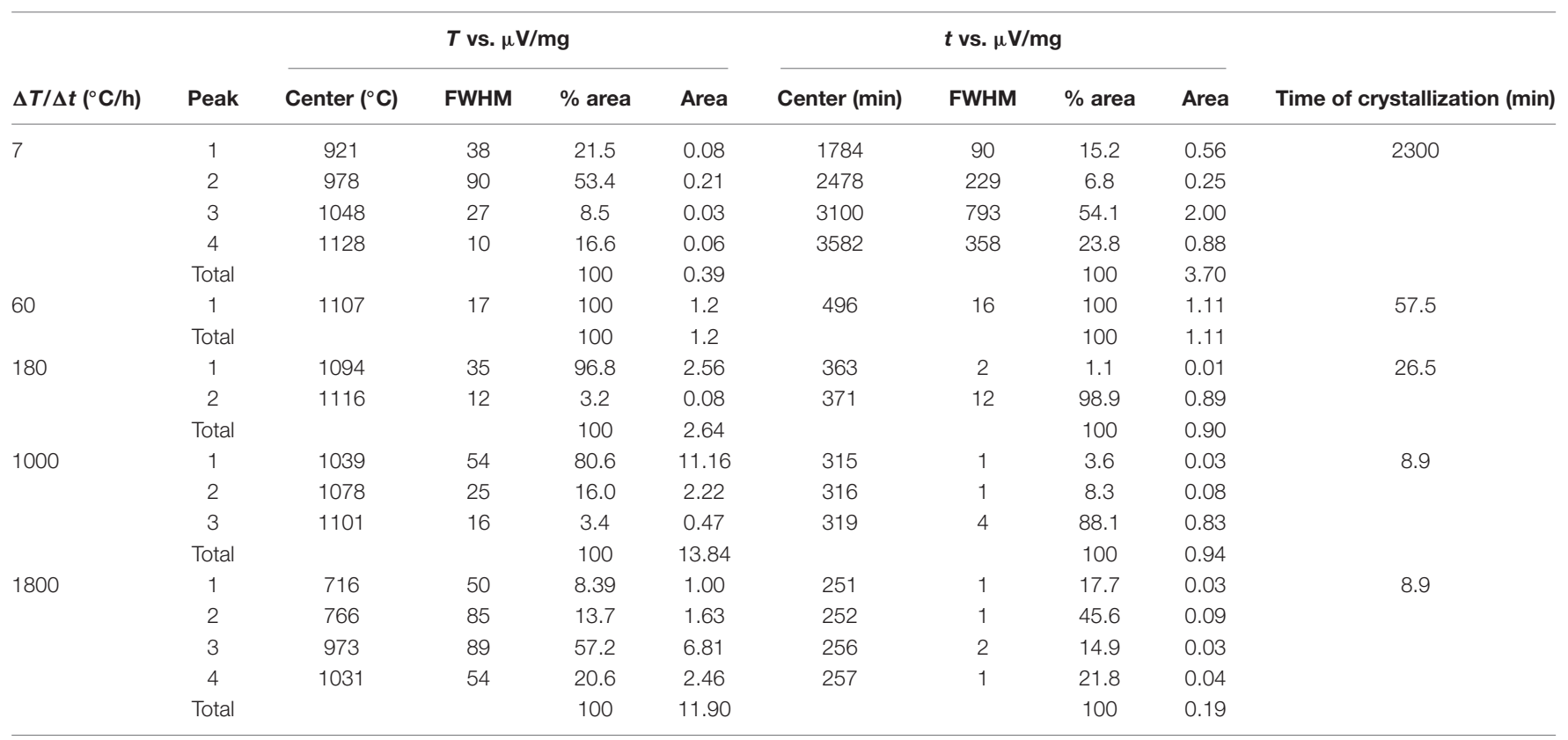

Individual peaks were fitted by pseudo-Voigt approximation with peak energy and full width at half maximum (FWHM) as seed values.

\section{Texture and Crystal-Chemistry}

Figure 3 displays the textural features of the solidified DSC charges. These products contain crystals of spinel (sp), clinopyroxene (cpx), melilite (mel) and/or plagioclase (only at $7^{\circ} \mathrm{C} / \mathrm{h}$ ), and glass. Sp crystals display always equant and faceted, hopper shapes. Conversely, cpx at $\Delta T / \Delta t$ of $7^{\circ} \mathrm{C} / \mathrm{h}$ are almost faceted and prismatic, frequently attaching on sp or pre-existing cpx crystals (Figure 3), while cpx obtained at $\Delta T / \Delta t \geq 60^{\circ} \mathrm{C} / \mathrm{h}$ show dendritic forms with fern-like elongated shapes. Mel crystallizes with either elongated $\mathrm{H}$-shapes or razor blade-like aspects (Figure 3 ).

Figure 4 and Table 4 report the quantitative abundance of phases. The amount of sp comprises a very low area\% of between 0.1 and 1.9, while that of cpx increases from 32.1 to 47.3 area\% as $\Delta T / \Delta t$ increases from 7 to $1800^{\circ} \mathrm{C} / \mathrm{h}$. The abundance of mel is also limited and changes from 5.3 to 8.9 and finally to 1.9 area\%, following a broad and asymmetric Gaussian-like trend. Plg occurs only at $\Delta T / \Delta t$ of $7^{\circ} \mathrm{C} / \mathrm{h}$ with an amount of 1.7 area\%. Overall the whole glass content monotonically decreases with increasing
$\Delta T / \Delta t$ (Table 4), reflecting the slight increase of the total crystal content (Figure 4 and Table 4 ).

The analyses of chemical attributes of phases are reported in Figure 5 and Supplementary Table S1. As the $\Delta T / \Delta t$ increases, all the major oxides of cpx, mel, and glass approach those of the starting composition. In particular, cpx records an increase in $\mathrm{SiO}_{2}, \mathrm{Al}_{2} \mathrm{O}_{3}$, and $\mathrm{Na}_{2} \mathrm{O}$ contents, and a decrease in $\mathrm{MgO}$ and $\mathrm{CaO}$, while $\mathrm{FeO}$ remains almost constant. Intra-crystalline glass follows the opposite trends of cpx, whereas those of $\mathrm{sp}$ are limited (Figure 5). The relatively highest (>10 wt.\%) chemical variations are recorded for mel: indeed, as the $\Delta T / \Delta t$ augments, $\mathrm{SiO}_{2}$ increases, and both $\mathrm{FeO}+\mathrm{MgO}$ decrease, whilst $\mathrm{Na}_{2} \mathrm{O}+\mathrm{CaO}$ are almost constant; $\mathrm{Al}_{2} \mathrm{O}_{3}$ follows an irregular decreasing trend (Figure 5).

\section{DISCUSSION}

Phase relations and crystal contents from our DSC experiments can be conveniently compared with those from previous ex situ 


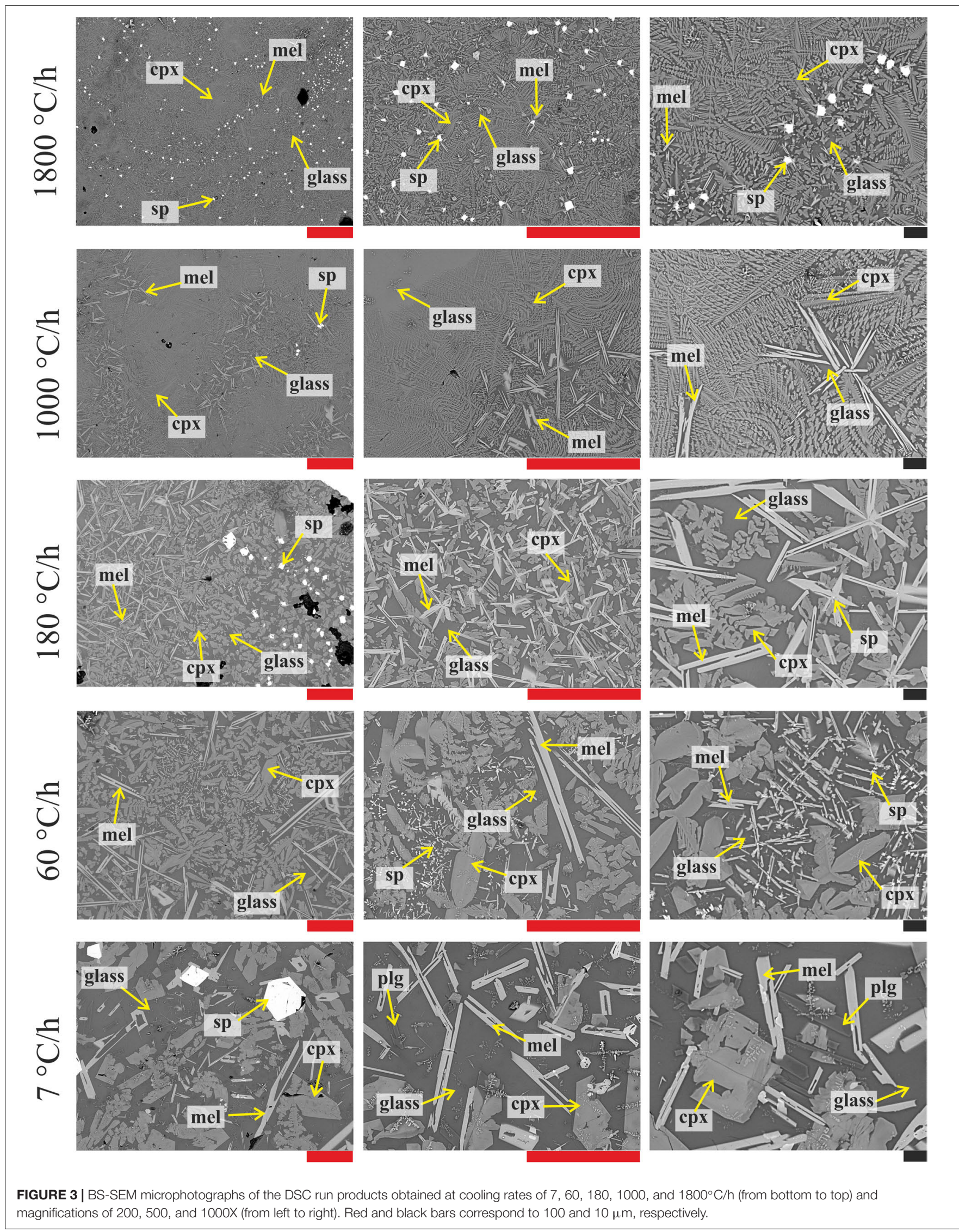




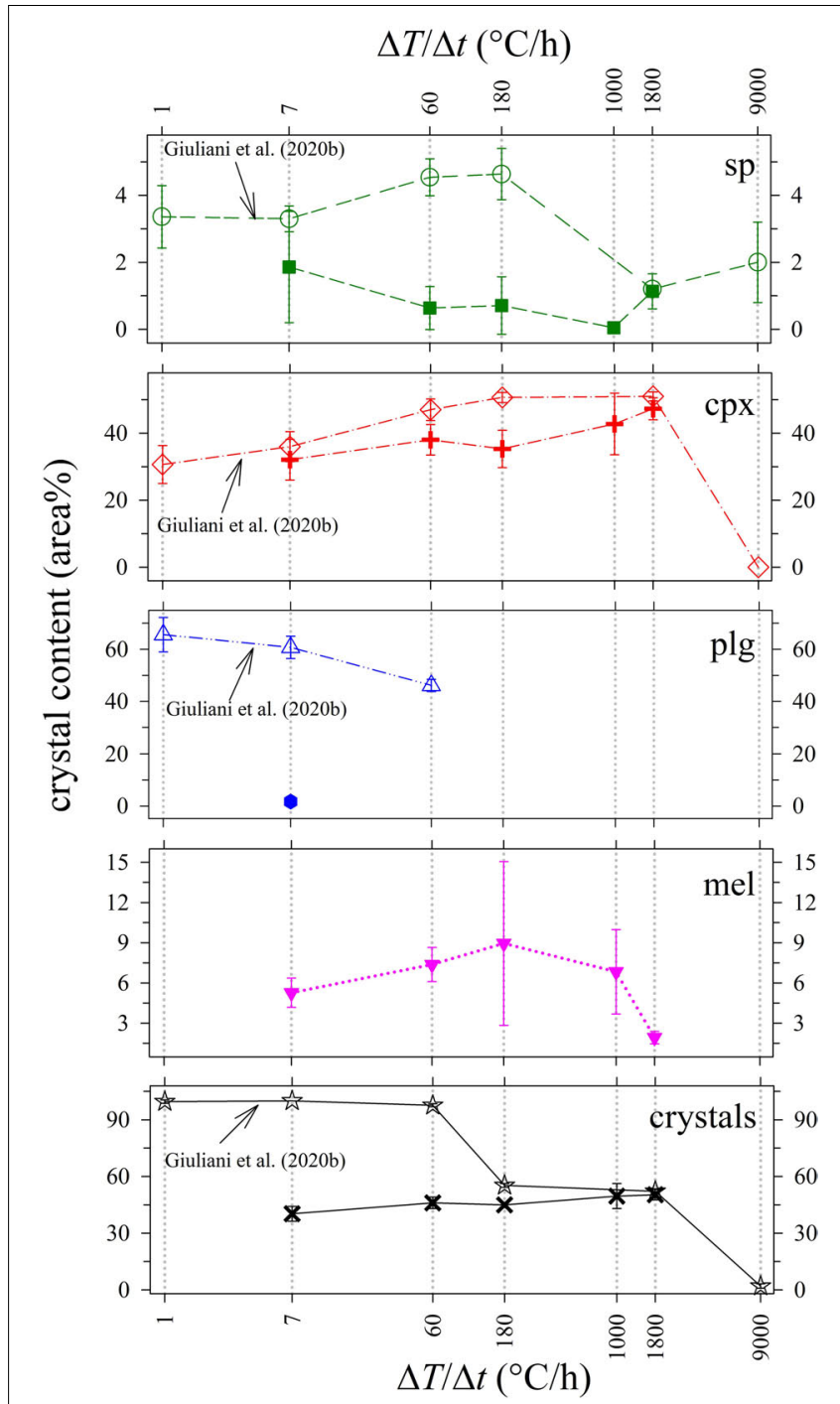

FIGURE 4 | Crystal content (area\%) vs $\Delta T / \Delta t\left({ }^{\circ} \mathrm{C} / \mathrm{h}\right)$ of in situ DSC experiments compared with ex situ cooling rate experiments from Giuliani et al. (2020b).

cooling rate experiments conducted by Vetere et al. $(2013,2015)$ and further analyzed by Giuliani et al. (2020b), run at similar solidification conditions. As shown in Figure 4, the amount of sp in the DSC run products is low (0-2 area\%), and comparable with $2-5$ area\% content quantified by Giuliani et al. (2020b). Also, the amount of cpx in DSC run products increases with increasing $\Delta T / \Delta t$ in a similar manner to that observed in Giuliani et al. (2020b). The cpx contents at $\Delta T / \Delta t$ of 7 and $1800^{\circ} \mathrm{C} / \mathrm{h}$ are practically identical, whilst those at $\Delta T / \Delta t$ of 60 and $180^{\circ} \mathrm{C} / \mathrm{h}$ differ by 5 and 10 area\%, respectively (Figure 4 ). Therefore, the crystallization of $\mathrm{sp}$ and cpx is well comparable with the ex situ dynamic experiments run in furnaces.

By contrast, in DSC run products, mel is $<10$ area $\%$, and plg is low to absent (Table 4 and Figure 4). The different amount of plg between the DSC experiments and those reported in Vetere
TABLE 4 | Phase proportions (area\%); standard deviations in parenthesis.

\begin{tabular}{lcccccc}
\hline $\boldsymbol{\Delta} \boldsymbol{T} / \boldsymbol{\Delta} \boldsymbol{t}\left({ }^{\circ} \mathbf{C} / \mathbf{h}\right)$ & Glass & $\mathbf{s p}$ & $\mathbf{c p x}$ & $\mathbf{p l g}$ & mel & Crystals \\
\hline 7 & $59.7(3.9)$ & $1.9(1.7)$ & $32.1(6.1)$ & $1.7(0.7)$ & $5.3(1.1)$ & $38.2(6.7)$ \\
60 & $53.9(3.0)$ & $0.6(0.6)$ & $38.0(4.5)$ & - & $7.3(1.3)$ & $44.8(3.6)$ \\
180 & $55.0(1.5)$ & $0.7(0.9)$ & $35.3(5.6)$ & - & $8.9(6.1)$ & $46.2(3.4)$ \\
1000 & $50.4(6.6)$ & $0.1(0.1)$ & $42.7(9.2)$ & - & $6.8(3.1)$ & $49.6(6.6)$ \\
1800 & $49.7(2.7)$ & $1.1(0.5)$ & $47.3(3.3)$ & - & $1.9(0.5)$ & $50.3(2.7)$
\end{tabular}

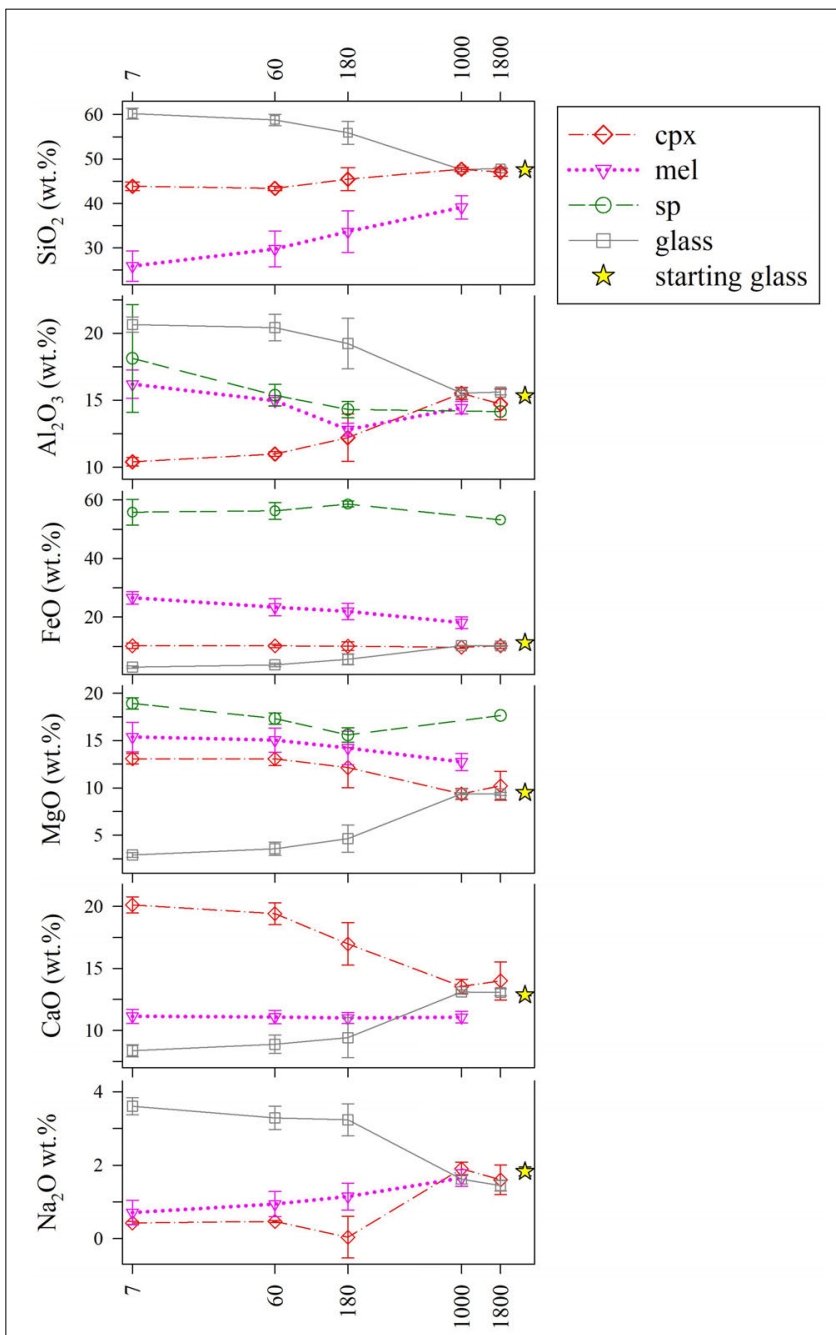

FIGURE 5 | Chemical variations of major oxides (wt.\%) in cpx, mel, sp, and intra-crystalline glass as a function of $\Delta T / \Delta t\left({ }^{\circ} \mathrm{C} / \mathrm{h}\right)$. Average data are listed in Supplementary Table S1.

et al. (2015) and Giuliani et al. (2020b) can be interpreted in the frame of the TTT diagrams (Lasaga, 1998; Shelby, 2005; Wang et al., 2012; Vetere et al., 2013). In a TTT diagram ( $t$ vs. $T)$, the nucleation rate $(I)$, the degree of undercooling $(\Delta T)$, and the time required to initiate nucleation of a crystalline phase ( $\tau$ or induction time) are strictly related (Lasaga, 1998; Fokin et al., 2003, 2008; Roskosz et al., 2005; Iezzi et al., 2009). At the apex of the TTT curve, the nucleation rate is strongly variable and has its maximum value $\left(I_{\max }\right)$, while $\tau$ is 
minimum. For the basaltic composition investigated here, the $\Delta T$ is moderate at temperatures of $1000-1100^{\circ} \mathrm{C}$ (Vetere et al., 2013). When a $\Delta T / \Delta t$ trajectory is close to $I_{\max }$, even small thermal (fluctuations and/or gradient) and/or mechanical (flowing and/or deformation) perturbations can produce significant changes of the nucleation of crystalline phases and their rate (Kirkpatrick, 1983; Vetere et al., 2013).

We hypothesize that during in situ DSC experiments the temperature oscillations were extremely low or even absent, indeed lower than those experienced by charges run by Vetere et al. (2013, 2015). This resulted in unfavorable conditions for the crystallization of a $\mathrm{SiO}_{2}$ - and tetrahedral connectedrich crystal, like plg. Indeed, extremely stable thermal and/or mechanical conditions favor the metastable nucleation of mel, a sorosilicate with lower $\mathrm{SiO}_{2}$ amount, and poorly connected tetrahedra. It is a note of worth that mel solidified also in the $\mathrm{B}_{100}$ experimental charges solidified ex situ at $\Delta T / \Delta t>60^{\circ} \mathrm{C} / \mathrm{h}$, by Vetere et al. (2013, 2015), although with a smaller content. These considerations attest that the plg phase is stable only at low $\Delta T / \Delta t$, where kinetics conditions are moderate to low, in agreement with Lange et al. (1994), and is more reluctant to nucleate than mel (Kirkpatrick, 1983; Vetere et al., 2015). Thereby, mel oversteps plg due to its lower $\mathrm{SiO}_{2}$ content and degree of polymerization (Kirkpatrick, 1983; Lasaga, 1998; Zhang et al., 2003; Iezzi et al., 2009, 2014). On these bases, the common presence of plg in natural tholeiitic rocks could be also related to the presence of thermal and mechanical perturbations (Chakraborty, 1995; Lasaga, 1998; Vetere et al., 2013), while the rarity of mel in basaltic rocks (Deer et al., 1992) is due to the relatively high $\mathrm{SiO}_{2}$ content of these magmas and the inevitable presence of thermal and mechanical perturbations. All these hypotheses are corroborated by recent findings by Tripoli et al. (2019) and Kolzenburg et al. (2020) on the role of mechanical perturbations on nucleation in solidifying basaltic liquids. They reported that flowing and stress on solidifying basaltic melts promote gradients in chemical potential, enhance the diffusion rates, and, consequently, increasing the crystallization (nucleation and growth) rates and reduced the incubation time. This also favors the kinetic crystallization of metastable phases, rather than the thermodynamically favored ones (Tripoli et al., 2019).

Thereby, we suggest that in the DSC facility used in this study, contrarily to those observed in Giuliani et al. (2020b), the thermal and/or mechanical fluctuations were extremely low or even absent, disfavoring the chemical diffusion of elements. Such conditions did not favor the nucleation of plg, especially at moderate to high cooling conditions. In turn, mel nucleated under disequilibrium condition. Noteworthy, poor tetrahedralconnected cpx phases crystallized in the DSC apparatus and in Giuliani et al. (2020b) with similar behaviors (Figure 4).

Moreover, DSC experiments at $\Delta T / \Delta t$ of 1000 and $1800^{\circ} \mathrm{C} / \mathrm{h}$ indicate also that cpx heterogeneously nucleates on $\mathrm{sp}$, whereas mel develops around cpx-rich areas (Figure 3). Owing on these textural and chemical outcomes, the crystallization sequence in the analyzed basaltic composition is sp, cpx, mel, and \pm plg, in line with the interpretation of Vetere et al. (2015) and Giuliani et al. (2020b). This also agrees with the observation that the oxide amounts of mel and glass are anti-correlated (Figure 5); hence mel metastably crystallizes in the melt left behind the growth of sp and cpx. Finally, being the mel amount in the DSC charges very low ( $<10$ area\%, Table 4 ), sp and cpx highly reproducible, the representativeness of these DSC experimental outcomes is reliable, especially at high $T$ below the liquidus.

The crystal sizes of cpx, sp, and mel decrease as a function of $\Delta T / \Delta t$ (Table 5). As $\Delta T / \Delta t$ increases from 7 to $1800^{\circ} \mathrm{C} / \mathrm{h}$, the measured crystal size range decreases from $635-2$ to $38-1 \mu \mathrm{m}$,

TABLE 5 | 2D maximum $\left(L_{\max }\right)$, minimum $\left(L_{\min }\right)$ and averaged $\left(L_{a v},\right)$ crystal lengths, CSDs parameters $\left(m\right.$ and $\left.n_{0}\right)$, maximum $\left(G_{\max }\right)$ and average $\left(G_{C S D}\right)$ growth rates.

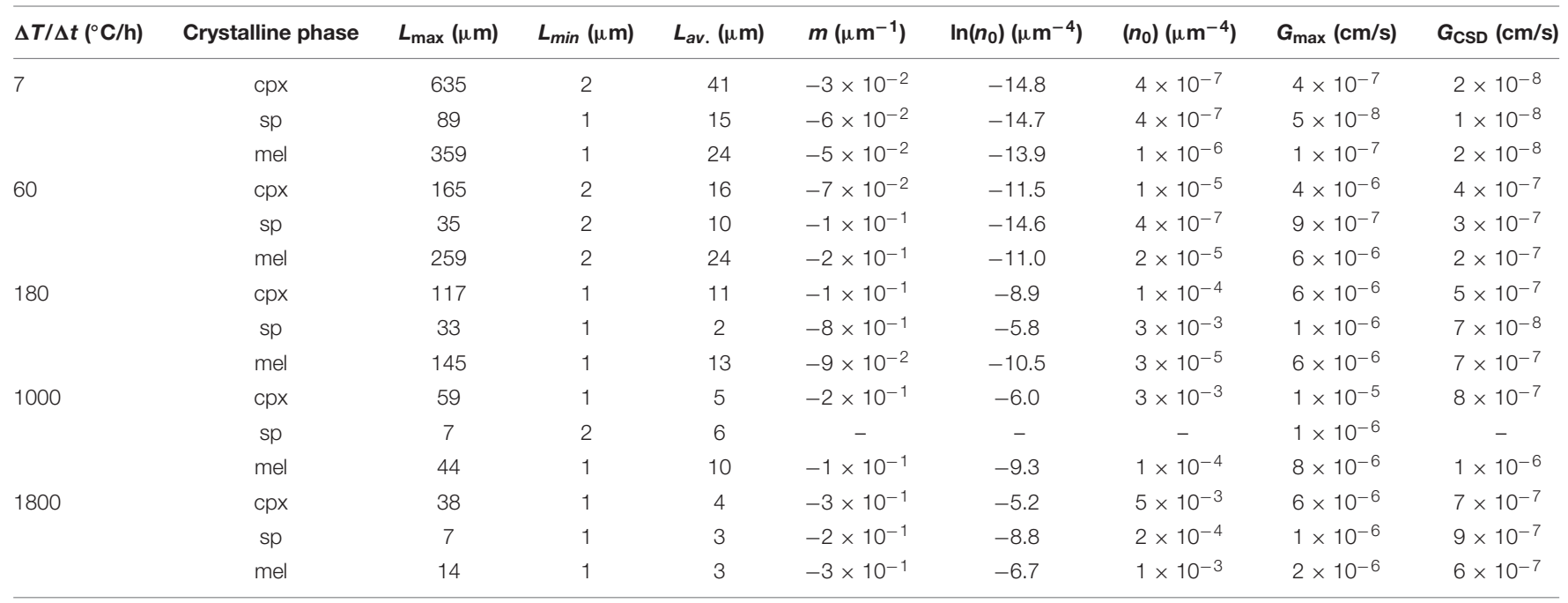

G values are obtained as $G_{\max }=L_{\max } / t$ and $G_{C S D}=-1 / m t$ (Zieg and Marsh, 2002). $L_{\max }$ is the average of the maximum lengths of five longest crystals, $m$ is the average CSD slope, and $t$ is the time of crystallization. In Giuliani et al. (2020b), $t$ was computed considering the time needed to cool the starting composition from 1233 ( $T_{m}$ ) to $800^{\circ} \mathrm{C}\left(T_{f}\right)$. For the DSC run products, $t$ has been directly measured on the crystallization peaks (Figure $2 B$ ), considering the crystallization time intervals reported in Table 3, i.e., $1677-1927 \mathrm{~min}\left(7^{\circ} \mathrm{C} / \mathrm{h}\right), 498-525 \mathrm{~min}\left(60^{\circ} \mathrm{C} / \mathrm{h}\right), 358-385 \mathrm{~min}\left(180^{\circ} \mathrm{C} / \mathrm{h}\right), 314-323 \mathrm{~min}\left(1000^{\circ} \mathrm{C} / \mathrm{h}\right), 250-259 \mathrm{~min}\left(1800^{\circ} \mathrm{C} / \mathrm{h}\right)$. 


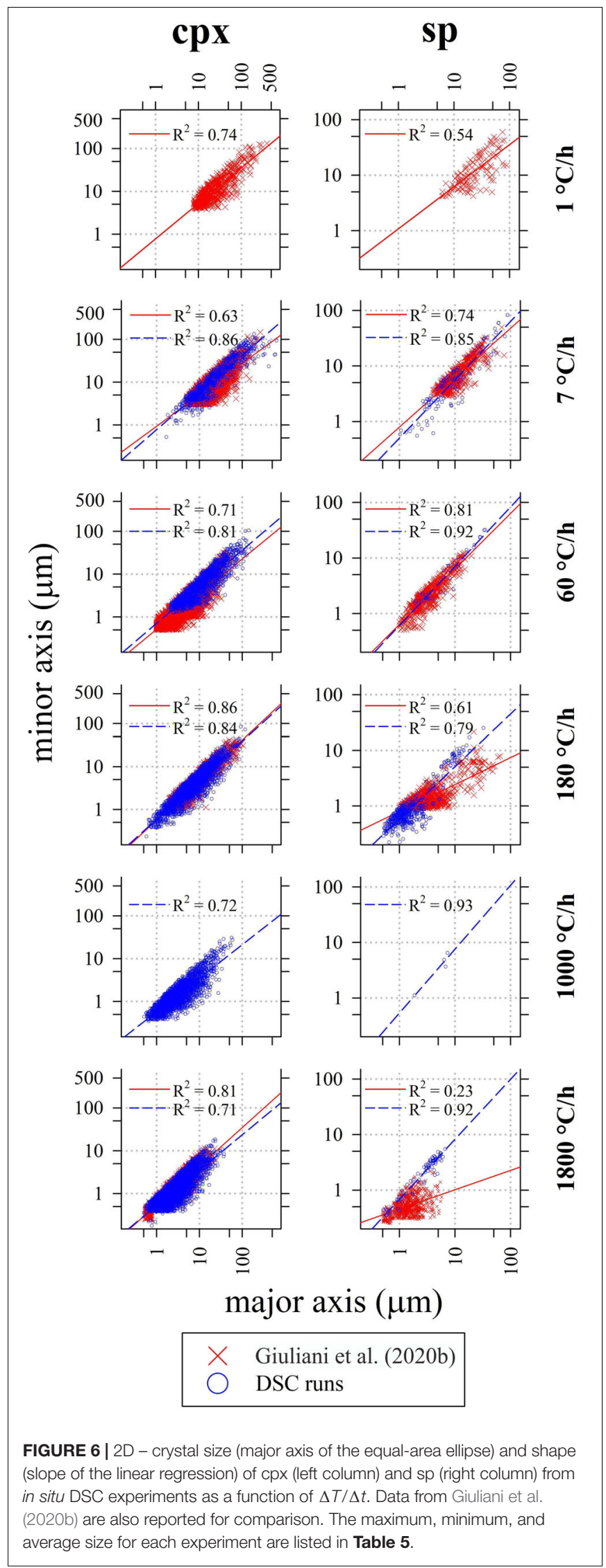

from 89-1 to 7-1 $\mu \mathrm{m}$, and from 359-1 to $14-1 \mu \mathrm{m}$ for cpx, sp, and mel, respectively (Table 5). Notably, the crystal sizes measured for sp and cpx from in situ DSC experiments are also comparable to those quantified by ex situ cooling rate experiments analyzed by Giuliani et al. (2020b) (Figure 6).

Crystal size distribution curves of cpx and sp are displayed in Figure 7 and compared with those reported in Giuliani et al. (2020b). These curves allow to make three-dimensional

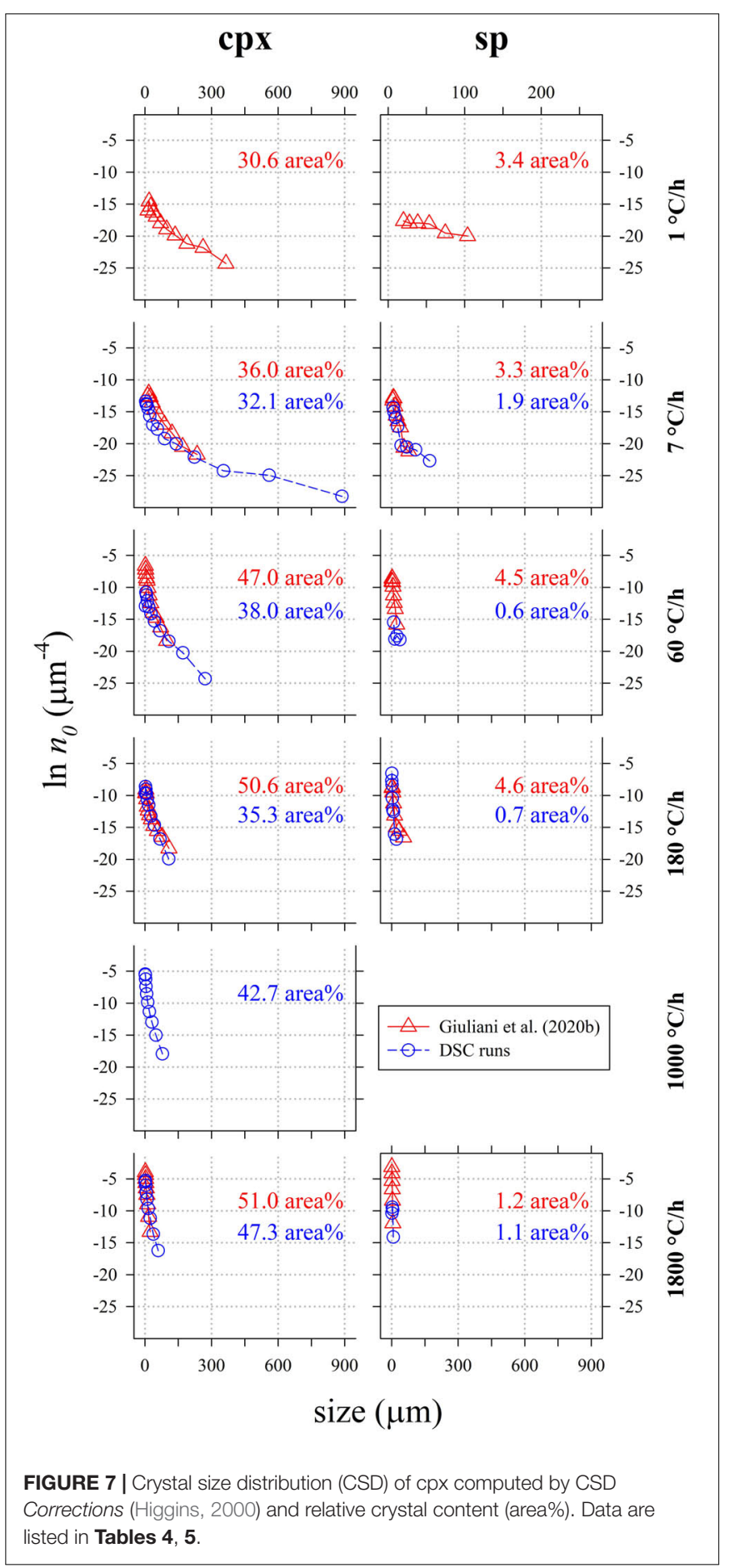


consideration about textures: they are computed using the $2 \mathrm{D}$ crystal sizes (maximum and minor axis), image area $\left(\mu \mathrm{m}^{2}\right)$, crystal shape and phase abundances (area\%); the stereological conversions are implemented in the software used to compute the CSDs (Higgins, 2006). Results show that with increasing $\Delta T / \Delta t$, the slope $(m)$ and crystal population density per size $\left(n_{0}\right.$, corresponding to the $y$-axis intercept) of cpx-CSD trajectories increase (Figure 7 and Table 5). These data well match with those reported in Giuliani et al. (2020b) for $\Delta T / \Delta t$ of 180 and $1800^{\circ} \mathrm{C} / \mathrm{h}$. Conversely, CSDs compared at $\Delta T / \Delta t$ of 7 and $60^{\circ} \mathrm{C} / \mathrm{h}$ show lower crystal sizes for the experimental charges analyzed by Giuliani et al. (2020b) due to the significant crystallization of plg. CSD curves obtained for sp from DSC experiments do not show a clear evolutionary trend as a function of $\Delta T / \Delta t$ and they poorly match with data from Giuliani et al. (2020b) (Figure 7). Overall, cpxand sp-CSD curves on the run-product cooled in the DSC at $\Delta T / \Delta t$ of 7 show both two log-linear segments with different slopes (Figure 7), accounting for multiple nucleation events and subsequent crystal growth by coarsening. The minimum slope corresponding to a maximum crystal size relates to the first nucleation event, further nucleation pulses at lower temperatures follow (Pupier et al., 2008; Giuliani et al., 2020b).
The other CSDs instead show a nearly unique log-linear evolution (Figure 7).

These considerations agree with the very rapid crystallization, on the order of minutes, measured in situ by Polacci et al. (2018) using $\mathrm{X}$-ray tomography. They rapidly cooled a natural basalt from $1250^{\circ} \mathrm{C}$ (superliquidus condition) to 1170 and $1150^{\circ} \mathrm{C}$ (low to moderate $\Delta T$ ), maintaining the final temperature for $4 \mathrm{~h}$. During the annealing at 1150 and $1170^{\circ} \mathrm{C}$, it is possible to identify at least three discrete nucleation events for sp and cpx. Also, Polacci et al. (2018) observed the heterogeneous crystallization of cpx on sp. Similarly, DSC spectra from this study display discrete exothermic peaks of crystallization (Figure $\mathbf{1}$ and Supplementary Figures S1B-E), except for the charges at $7^{\circ} \mathrm{C} / \mathrm{h}$, showing a complex and broad DSC multicomponent band at a relatively low thermal range $\left(911-1062^{\circ} \mathrm{C}\right)$, that suggests the attainment of a continuous crystallization process (Figure 1 and Supplementary Figure S1A). In line with this, a long tail at large crystal sizes $(>300 \mu \mathrm{m})$ along with low $m$ and $n_{0}$ values (Figure 7) characterize the CSD curve of this experiment. Possibly, the exothermic multicomponent band and the long CSD tail observed at $\Delta T / \Delta t$ of $7^{\circ} \mathrm{C} / \mathrm{h}$ are both determined by crystal coarsening phenomena. It is thus possible to assume that nucleation occurs mainly by a rapid pulse during cooling and

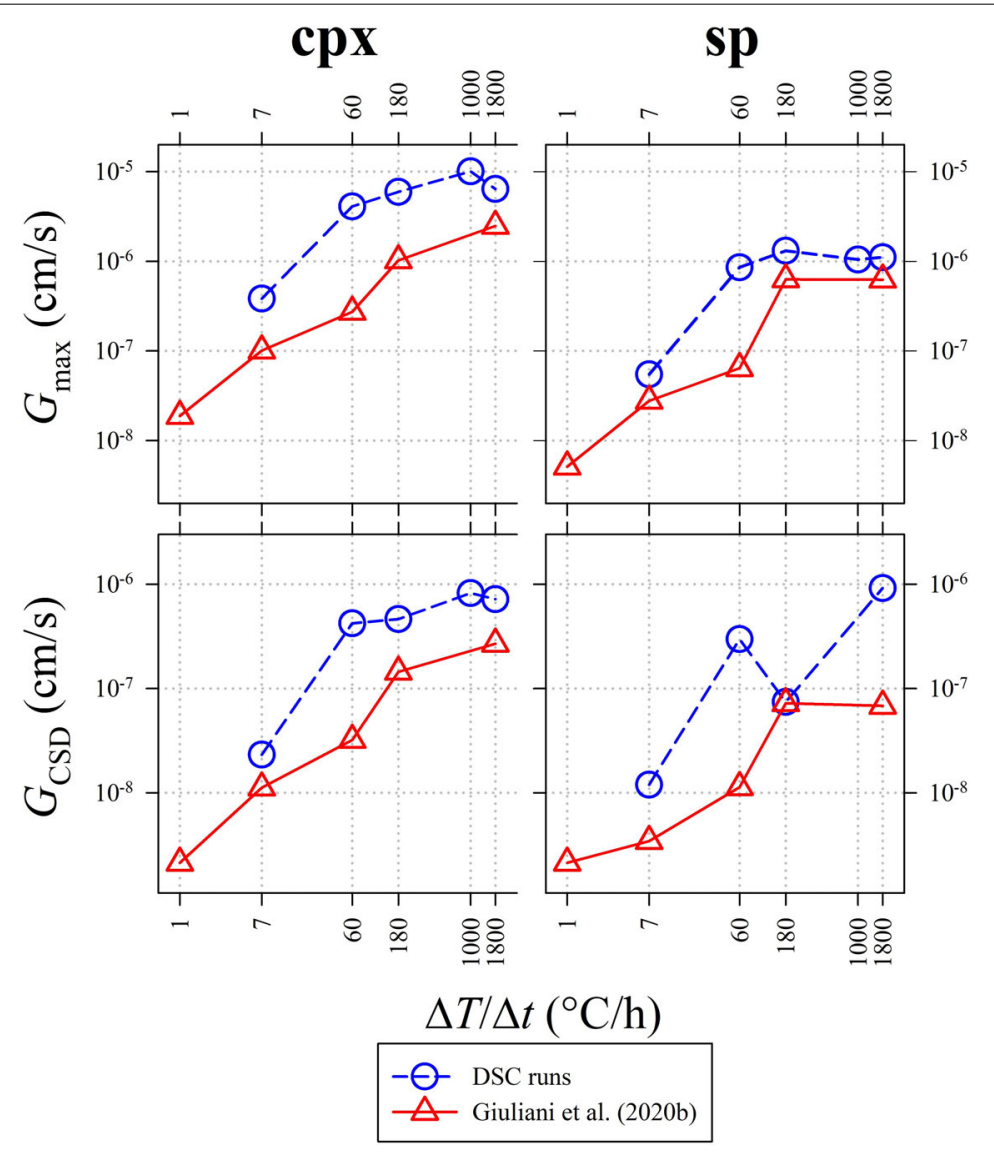

FIGURE 8 | Variation of the maximum growth rate $\left(G_{\max }\right.$; top) and the average CSD growth rate $\left(G_{C S D}\right.$; bottom). Data from DSC experiments (Table 5) are compared with those reported in Giuliani et al. (2020b). 


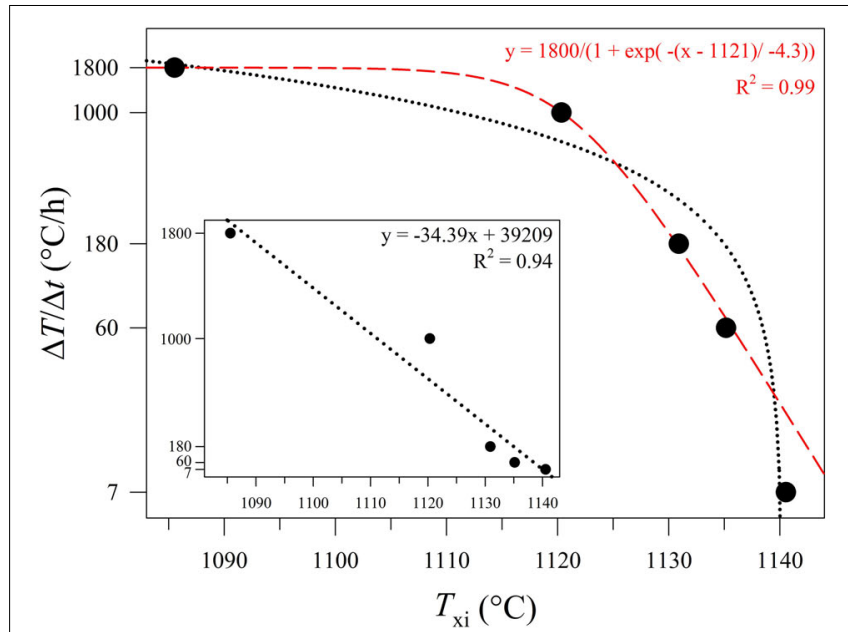

FIGURE 9 $\mid T_{\mathrm{xi}}$ versus $\Delta T / \Delta t\left({ }^{\circ} \mathrm{C} / \mathrm{h}\right)$ according to data reported in Table 1, Figures 1, and Supplementary Figures S1A-E. As the cooling rate increase, the onset temperature of crystal nucleation decreases. The dotted black line refers to a linear regression fit. The dashed red line refers to an exponential regression fit.
Giuliani et al., 2020b). In particular, the average $L_{\max }$ has been divided by the actual crystallization time $(t)$ measured from the DSC spectra (Figures 1, 2B and Table 3). The average growth rate $\left(G_{\mathrm{CSD}}\right)$ has been also determined by interpolating $m$ (Table 5) with $t$, as $G_{\mathrm{CSD}}=-1 / m t$ (Zieg and Marsh, 2002; Giuliani et al., $2020 b)$. The values of $G_{\max }$ and $G_{C S D}$ from this study are reported in Table 5 and plotted in Figure 8, together with the $G_{\max }$ and $G_{\text {CSD }}$ from Giuliani et al. (2020b). Both the $G$ s of cpx and sp obtained from DSC experiments are systematically higher than those measured by ex situ cooling rate experiments (Figure 8), due to a more accurate and reliable estimate of $t$ from DSC spectra (Figures 1, 2B and Table 3). Generally, $G_{\max }$ and $G_{C S D}$ increase as a function of $\Delta T / \Delta t$, with the only exception of $G_{\mathrm{CSD}}$ of $\mathrm{sp}$ derived at $\Delta T / \Delta t$ between 60 and $180^{\circ} \mathrm{C} / \mathrm{h}$ (Figure 8).

The values of $T_{\mathrm{xi}}$ (Table 2) vs. $\Delta T / \Delta t$ are reported in Figure 9, showing a decreasing exponential evolution that highlights the faster decrease of $T_{\mathrm{xi}}$ at higher kinetic conditions, with respect to low $\Delta T / \Delta t$. Results of data fitted using linear regression a high correlation too. Importantly, these experimental data and the fitting exponential equation have been used to reconstruct the uppermost portion of a TTT curve of the basaltic melt solidifying at ambient conditions (Figure 10). According to Vetere et al. (2015), a cooling rate of $9000^{\circ} \mathrm{C} / \mathrm{h}$ prevents the crystallization (crystals $<2$ area\%) of a basaltic liquid. Since dynamic stress conditions in volcanic systems enhance the nucleation process (Kouchi et al., 1986; Vona and Romano, 2013; Kolzenburg et al., 2018a,b, 2020; Vetere et al., 2020), the TTT data from this study represent the conservative expression of a kinetic crystallization process governed by cooling rate.

that mainly, at low rates, crystal coarsening becomes a dominant solidification process.

Calculation of the maximum growth rate $\left(G_{\max }\right)$ uses the maximum lengths $\left(L_{\max }\right)$ of five longest crystals (Burkhard, 2002; Hammer and Rutherford, 2002; Couch, 2003; Iezzi et al., 2011; 


\section{CONCLUSION}

We present a complete and quantitative characterization of a basaltic melt solidifying from liquidus to solidus conditions, monitored in situ via DSC heating/cooling experiments, able to track the thermal evolution and crystallization path of the system. Direct measurement of the onset temperature of crystallization makes possible to define the nucleation and growth processes in an interval of $911-1129^{\circ} \mathrm{C}$, at atmospheric pressure and fugacity of air. Textural analysis of cpx and sp shows that both $m$ and $n_{0}$ of CSDs increase with increasing $\Delta T / \Delta t$, while the crystal size ranges decrease. These data point out that the $\mathrm{sp}$ nucleation favors those of cpx; at the slow kinetic condition, cpx formation happens by multiple nucleation events, followed by crystal coarsening.

The $T_{\mathrm{xi}}$ depicts a decreasing exponential trend as a function of cooling rate; under low kinetic conditions, the onset of nucleation starts after a long time at high temperature (low $\Delta T$ ), as expected from theory. The $T_{\mathrm{xi}}$ values measured and/or computed using the founded analytical function define the uppermost part of a TTT-like trend, making it possible to quantitatively model the crystallization path of a basaltic melt solidifying at ambient conditions.

\section{DATA AVAILABILITY STATEMENT}

All datasets generated for this study are included in the article/Supplementary Material.

\section{AUTHOR CONTRIBUTIONS}

LG acquired BS-SEM images, performed the image analysis and, together with GI, organized the data in tables and

\section{REFERENCES}

Applegarth, L. J., Tuffen, H., James, M. R., and Pinkerton, H. (2013). Degassingdriven crystallisation in basalts. Earth Sci. Rev. 116, 1-16. doi: 10.1016/j. earscirev.2012.10.007

Armienti, P., Pareschi, M. T., Innocenti, F., and Pompilio, M. (1994). Effect of magma storage and ascent on kinetics of crystal growth. Contrib. Mineral. Petrol. 115, 402-414. doi: 10.1007/bf00320974

Arzilli, F., Agostini, C., Landi, P., Fortunati, A., Mancini, L., and Carroll, M. R. (2015). Plagioclase nucleation and growth kinetics in a hydrous basaltic melt by decompression experiments. Contrib. Mineral. Petrol. 170:55. doi: 10.1007/ s00410-015-1205-1209

Arzilli, F., La Spina, G., Burton, M. R., Polacci, M., Le Gall, N., Hartley, M. E., et al. (2019). Magma fragmentation in highly explosive basaltic eruptions induced by rapid crystallization. Nat. Geosci. 12, 1023-1028. doi: 10.1038/s41561-0190468-466

Baker, D. R., Brun, F., O’Shaughnessy, C., Mancini, L., Fife, J. L., and Rivers, M. (2013). A four-dimensional X-Ray tomographic microscopy study of bubble growth in basaltic foam. Nat. Commun. 3:1135. doi: 10.1038/ncomms 2134

Burkhard, D. J. (2003). Thermal interaction between lava lobes. Bull. Volvanol. 65, 136-143. doi: 10.1007/s00445-002-0249-247

Burkhard, D. J. (2005). Nucleation and growth rates of pyroxene, plagioclase and Fe-Ti oxides in basalt under atmospheric conditions. Eur. J. Minral. 17, 675-685. doi: 10.1127/0935-1221/2005/0017-0675 figures, and wrote an early version of the manuscript. GI conceived the study. TH, MD, and AE carried out the DSC experiments. $\mathrm{MN}$ contributed to the BS-SEM acquisition. All the authors discussed together the data and their interpretation, as well as contributed to the attainment of this final version.

\section{FUNDING}

This study was funded by the "Fondi Ateneo of the University G. D’Annunzio”, PRIN (2009PZ47NA_003) project "Experimental determination of the glassforming ability (GFA), nucleation and crystallization of natural silicate melts" and PRIN (2017J277S9_003) project "Time scales of solidification in magmas: Application to Volcanic Eruptions, Silicate Melts, Glasses, Glass-Ceramics" awarded to GI. Alexander von Humboldt foundation senior research grant to $\mathrm{FV}$ is also acknowledged.

\section{ACKNOWLEDGMENTS}

The authors thank the editor YX and the two reviewers. Most of this study was conducted during the Ph.D. of LG.

\section{SUPPLEMENTARY MATERIAL}

The Supplementary Material for this article can be found online at: https://www.frontiersin.org/articles/10.3389/feart. 2020.00337/full\#supplementary-material

Burkhard, D. J. M. (2001). Crystallization and oxidation of Kilauea basalt glass: processes during reheating experiments. J. Petrol. 42, 507-527. doi: 10.1093/ petrology/42.3.507

Burkhard, D. J. M. (2002). Kinetics of crystallization: example of microcrystallization in basalt lava. Contrib. Mineral. Petrol. 142, 724-737. doi: 10. 1007/s00410-001-0321-x

Cashman, K. V. (1993). Relationship between plagioclase crystallization and cooling rate in basaltic melts. Contrib. Mineral. Petrol. 113, 126-142. doi: 10.1007/bf00320836

Castro, J. M., Beck, P., Tuffen, H., Nichols, A. R. L., Dingwell, B., and Martin, M. C. (2008). Timescales of spherulite crystallization in obsidian inferred from water concentration profiles. Am. Min. 93, 1816-1822. doi: 10.2138/am.2008.2904

Chakraborty, S. (1995). "Diffusion in silicate melts," in Structure And Dynamics of Silicate Melts. Review in Mineralogy and Geochemistry, eds J. F. Stebbins, D. B. Dingwell, and P. W. McMillan, (Cham: Springer), 441-497.

Couch, S. (2003). Experimental investigation of crystallization kinetics in a haplogranite system. Am. Min. 88, 1471-1485. doi: 10.2138/am-2003-1011

Deer, W. A., Howie, R. A., and Zussman, J. (1992). An Introduction To The Rock-Forming Minerals. Upper Saddle River, NJ: Prentice Hall.

Del Gaudio, P., Mollo, S., Ventura, G., Iezzi, G., Taddeucci, J., and Cavallo, A. (2010). Cooling rate-induced differentiation in anhydrous and hydrous basalts at $500 \mathrm{MPa}$ : implications for the storage and transport of magmas in dykes. Chem. Geol. 270, 164-178. doi: 10.1016/j.chemgeo.2009.11.014

Dingwell, D. B., and Webb, S. L. (1990). Relaxation in silicate melts. Eur. J. Mineral. 2, 427-449. 
Fiege, A., Vetere, F., Iezzi, G., Simon, A., and Holtz, F. (2015). The roles of decompression rate and volatiles $(\mathrm{H} 2 \mathrm{O}+\mathrm{Cl} \pm \mathrm{CO} 2 \pm \mathrm{S})$ on crystallization in (trachy-) basaltic magma. Chem. Geol. 411, 310-322. doi: 10.1016/j.chemgeo. 2015.07.016

Fokin, V. M., Yuritsyn, N. S., Zanotto, E. D., Schmelzer, J. W. P., and Cabral, A. A. (2008). Nucleation time-lag from nucleation and growth experiments in deeply undercooled glass-forming liquids. J. Non Crystal. Solids 354, 3785-3792. doi: 10.1016/j.jnoncrysol.2008.05.011

Fokin, V. M., Zanotto, E. D., and Schmelzer, J. W. P. (2003). Homogeneous nucleation versus glass transition temperature of silicate glasses. J. Non Crystal. Solids 321, 52-65. doi: 10.1016/S0022-3093(03)00089-89

Giuliani, L., Iezzi, G., and Mollo, S. (2020a). Dynamics of volcanic systems: physical and chemical models applied to equilibrium versus disequilibrium solidification of magmas. AGU Books 16, 373-418.

Giuliani, L., Iezzi, G., Vetere, F., Behrens, H., Mollo, S., Cauti, F., et al. (2020b). Evolution of textures, crystal size distributions and growth rates of plagioclase, clinopyroxene and spinel solidified at variable cooling rates from a mid-ocean ridge basaltic liquid. Earth Sci. Rev. 204:103165. doi: 10.1016/j.earscirev.2020. 103165

Hammer, J. E. (2008). "Experimental studies of the kinetics and energetics of magma crystallization," in Minerals, Inclusions and Volcanic Processes. Reviews in Mineralogy and Geochemistry, eds K. D. Putirka, and F. J. Tepley, (Washington, DC: Mineralogical Society of America and Geochemical Society), 9-59. doi: 10.2138/rmg.2008.69.2

Hammer, J. E., and Rutherford, M. J. (2002). An experimental study of the kinetics of decompression-induced crystallization in silicic melt. J. Geophys. Res. 107:2021.

Higgins, M. D. (2000). Measurement of crystal size distributions. Am. Min. 85, 1105-1116. doi: 10.2138/am-2000-8-901

Higgins, M. D. (2006). Quantitative Textural Measurement In Igneous And Metamorphic Petrology. Cambridge: Cambridge University Press.

Iezzi, G., Elbrecht, A. L., Davis, M., Vetere, F., Misiti, V., Mollo, S., et al. (2017). Glass Stability (GS) of chemically complex (natural) sub-alkaline glasses. J. Non Crystal. Solids 477, 21-30. doi: 10.1016/j.jnoncrysol.2017.09.047

Iezzi, G., Mollo, S., Shaini, E., Cavallo, A., and Scarlato, P. (2014). The cooling kinetics of plagioclase revealed by electron microprobe mapping. Am. Min. 99, 898-907. doi: 10.2138/am.2014.4626

Iezzi, G., Mollo, S., Torresi, G., Ventura, G., Cavallo, A., and Scarlato, P. (2011). Experimental solidification of an andesitic melt by cooling. Chem. Geol. 283, 261-273. doi: 10.1016/j.chemgeo.2011.01.024

Iezzi, G., Mollo, S., and Ventura, G. (2009). "Solidification behavior of natural silicate melts and volcanological implications," in Volcanoes: Formation, Eruptions And Modeling, eds N. Lewis, and A. Moretti, (New York, NY: Nova publishers), 127-151.

Kirkpatrick, R. J. (1983). Theory of nucleation in silicate melts. Am. Min. 68, 66-77.

Klein, L., Onorato, P. I. K., Uhlmann, D. R., and Hopper, R. W. (1975). Viscous flow, crystallization behavior and thermal histories of lunar breccias 70019 and 79155. Proc. Lunar. Sci. Conf. 4, 579-593.

Kolzenburg, S., Di Genova, D., Giordano, D., Hess, K. U., and Dingwell, D. B. (2018a). The effect of oxygen fugacity on the rheological evolution of crystallizing basaltic melts. Earth Planet. Sci. Lett. 487, 21-32. doi: 10.1016/j. epsl.2018.01.023

Kolzenburg, S., Giordano, D., Hess, K. U., and Dingwell, D. B. (2018b). Shear rate-dependent disequilibrium rheology and dynamics of basalt solidification. Geophys. Res. Lett. 45, 6466-6475. doi: 10.1029/2018GL077799

Kolzenburg, S., Giordano, D., Cimarelli, C., and Dingwell, D. B. (2016). Insitu thermal characterization of cooling/crystallizing lavas during rheology measurements and implications for lava flow emplacement. Geochim. Cosmochim. Acta 195, 244-258. doi: 10.1016/j.gca.2016.09.022

Kolzenburg, S., Hess, K. U., and Dingwell, D. B. (2020). Disequilibrium rheology and crystallization kinetics of basalts and implications for the Phlegrean volcanic District. Front. Earth Sci. 8:187. doi: 10.3389/feart.2020.00187

Kouchi, A., Tsuchiyama, A., and Sunagawa, I. (1986). Effect of stirring on crystallization kinetics of basalt: texture and element partitioning. Contrib. Min. Petrol. 93, 429-438. doi: 10.1007/bf00371713

Lange, R. A., Cashman, K. V., and Navrotsky, A. (1994). Direct measurements of latent heat during crystallization and melting of a ugandite and an olivine basalt. Contrib. Min. Petrol. 118, 169-181. doi: 10.1007/bf01052867
Lanzafame, G., Iezzi, G., Mancini, L., Lezzi, F., Mollo, S., and Ferlito, C. (2017). Solidification and turbulence (non-laminar) during magma ascent: insights from 2D and 3D analyses of bubbles and minerals in an Etnean dyke. J. Petrol. 58, 1511-1534. doi: 10.1093/petrology/egx063

Lanzafame, G., Mollo, S., Iezzi, G., Ferlito, C., and Ventura, G. (2013). Unravelling the solidification path of a pahoehoe "cicirara" lava from Mount Etna volcano. Bull. Volc. 75-4, 1-16. doi: 10.1007/s00445-013-0703-708

Lasaga, A. C. (1998). Kinetic theory in the Earth Sciences. New York, NY: Princenton university press.

Maumus, J., Bagdassarov, N., and Schmeling, H. (2005). Electrical conductivity and partial melting of mafic rocks under pressure. Geochim. Cosmochim. Acta 69, 4703-4718. doi: 10.1016/j.gca.2005.05.010

Mollo, S., and Hammer, J. E. (2017). "Dynamic crystallization in magmas," in Mineral Reaction Kinetics: Microstructures, Textures, Chemical And Isotopic Signatures. EMU Notes in Mineralogy, eds W. Heinrich, and R. Abart, (McLean: European Mineralogical Union), 1-46. doi: 10.1180/EMU-notes.16.12

Ni, H., Keppler, H., Walte, N., Schiavi, F., Chen, Y., Masotta, M., et al. (2014). In-situ observation of crystal growth in a basalt melt and development of crystal size distribution in igneous rocks. Contrib. Mineral. Petrol. 167:1003. doi: 10.1007/s00410-014-1003-9

Onorato, P. I. K., and Uhlmann, D. R. (1976). Nucleating heterogeneities and glass formation. J. Non Crystal. Solids 22, 367-378. doi: 10.1016/0022-3093(76) 90066-1

Onorato, P. I. K., Uhlmann, D. R., and Hopper, R. W. (1980). A kinetic treatment of glass formation: IV. Crystallization on reheating a glass. J. Non Crystal. Solids 41, 189-200. doi: 10.1016/0022-3093(80)90164-7

Polacci, M., Arzilli, F., La Spina, G., Le Gall, N., Cai, B., Hartley, M. E., et al. (2018). Crystallization in basaltic magmas revealed via in situ 4D synchrotron X-ray microtomography. Sci. Rep. 8:8377. doi: 10.1038/s41598-018-2664426646

Pupier, E., Duchene, S., and Toplis, M. J. (2008). Experimental quantification of plagioclase crystal size distribution during cooling of a basaltic liquid. Contrib. Mineral. Petrol. 155, 555-570. doi: 10.1007/s00410-007-0258259

Ray, C. S., Reis, S. T., Brow, R. K., Höland, W., and Rheinberger, V. (2005). A new DTA method for measuring critical cooling rate for glass formation. J. Non Crystal. Solids 351, 1350-1358. doi: 10.1016/j.jnoncrysol.2005.03.029

Ray, C. S., Reis, S. T., Sen, S., and O’Dell, J. S. (2010). JSC-1A lunar soil simulant: characterization, glass formation, and selected glass properties. J. Non Crystal. Solids 356, 2369-2374. doi: 10.1016/j.jnoncrysol.2010.04.049

Rogez, J., Papin, S., Benigni, P., and Jousseaume, C. (2017). "Thermodynamic of the glassy and crystalline states-general kinetic to return to equilibrium," in From Glass To Crystals. Nucleation, Growth And Phase Separation, From Research To Applications, eds D. R. Neuville, L. Cormier, D. Caurant, and L. Montagne, (France: EDP Sciences).

Roskosz, M., Toplis, M. J., and Richet, P. (2005). Experimental determination of crystal growth rates in highly supercooled aluminosilicate liquids. Implic. Rate Control. Process. Am. Min. 90, 1146-1156. doi: 10.2138/am.2005.1627

Scarlato, P., Poe, B. T., and Freda, C. (2004). High-pressure and high-temperature measurements of electrical conductivity in basaltic rocks from Mount Etna, Sicily, Italy. J. Geophys. Res. 109:B02210. doi: 10.1029/2003JB002666

Schiavi, F., Walte, N., and Keppler, H. (2009). First in-situ observation of crystallization processes in a basaltic-andesitic melt with the moissanite cell. Geology 37, 963-966. doi: 10.1130/G30087A.1

Shelby, J. E. (2005). Introduction To Glass Science And Technology, 2nd Edn, Padstow: Conwall.

Sunagawa, I. (1992). In situ investigation of nucleation, growth and dissolution of silicate crystals at high temperatures. Annu. Rev. Earth. Planet. Sci. 20, 113-142. doi: 10.1146/annurev.ea.20.050192.000553

Tripoli, B., Manga, M., Mayeux, J., and Barnard, H. (2019). The effects of deformation on the early crystallization kinetics of basaltic magmas. Front. Earth. Sci. 7:250. doi: 10.3389/feart.2019.00250

Uhlmann, D. R., Klein, L., Onorato, P. I. K., and Hopper, R. W. (1975). The formation of lunar breccias: sintering and crystallization kinetics. Proc. Lunar Sci. Conf. 45, 693-705.

Uhlmann, D. R., Klein, L., Onorato, P. I. K., and Scherer, G. W. (1979). “A simplified model for glass formation," in Proceedings of the Lunar and Planetary Science Conference, New York, NY. 
Uhlmann, D. R., Yinnon, H., and Fang, C. H. (1981). “Simplified model evaluation of cooling rates for glass-containing lunar composition," in Proceedings of the Lunar and Planetary Science Conference, Houston, TX.

Vetere, F., Iezzi, G., Behrens, H., Cavallo, A., Misiti, V., Dietrich, M., et al. (2013). Intrinsic solidification behavior of basaltic to rhyolitic melts: a cooling rate experimental study. Chem. Geol. 354, 233-242. doi: 10.1016/j.chemgeo.2013. 06.007

Vetere, F., Iezzi, G., Behrens, H., Holtz, F., Ventura, G., Misiti, V., et al. (2015). Glass forming ability and crystallization behavior of sub-alkaline silicate melts. Earth Sci. Rev. 150, 25-44. doi: 10.1016/j.earscirev.2015.07.001

Vetere, F., Mazzeo, A., Perugini, D., and Holtz, F. (2020). Viscosity behaviour of silicate melts during cooling under variable shear rates. J. Non Crystal. Solids 477, 21-30.

Vona, A., and Romano, C. (2013). The effect of undercooling and deformation rates on the crystallization kinetics of Stromboli and Etna basalts. Contrib. Mineral. Petrol. 166, 491-509. doi: 10.1007/s00410-013-0887-880

Vona, A., Romano, C., Dingwell, D. B., and Giordano, D. (2011). The rheology of crystal-bearing basaltic magmas from Stromboli and Etna. Geochim. Cosmochim. Acta 75, 3214-3236. doi: 10.1016/j.gca.2011.03.031

Wang, L., Liu, B., Li, H., Yang, W., Ding, Y., Sinogeikin, S. V., et al. (2012). Longrange ordered carbon clusters: a crystalline material with amorphous building blocks. Science 337:825. doi: 10.1126/science.1220522

Weinberg, M. C., and Zanotto, E. (1989). Re-examination of the temperature dependence of the classical nucleation rate: homogeneous crystal nucleation in glass. J. Non Crystal. Solids 108, 99-108. doi: 10.1016/0022-3093(89)90337-2

Xu, Y., Shankland, T. J., and Poe, B. T. (2000). Laboratory-based electrical conductivity in the Earth's mantle. J. Geophys. Res. 105, 895-827.
Zanatta, M., Cormier, L., Hennet, L., Petrillo, C., and Sacchetti, F. (2017). Real-time observation of the isothermal crystallization kinetics in a deeply supercooled liquid. Sci. Rep. 7:43671. doi: 10.1038/srep43671

Zhang, Y., Xu, Z., and Liu, Y. (2003). Viscosity of hydrous rhyolitic melts inferred from kinetic experiments, and a new viscosity model. Am. Min. 88, 1741-1752. doi: 10.2138/am-2003-11-1215

Zheng, Q., Zhang, Y., Montazerian, M., Gulbiten, O., Mauro, J. C., Zanotto, E. D., et al. (2019). Understanding glass through differential scanning calorimetry. Chem. Rev. 119, 7848-7939. doi: 10.1021/acs.chemrev.8b00510

Zieg, M. J., and Marsh, B. D. (2002). Crystal size distributions and scaling laws in the quantification of igneous texture. J. Petrol. 43, 85-101. doi: 10.1093/ petrology/43.1.85

Conflict of Interest: TH, MD, and AE were employed by the company Schott Glass North America.

The remaining authors declare that the research was conducted in the absence of any commercial or financial relationships that could be construed as a potential conflict of interest.

Copyright (c) 2020 Giuliani, Iezzi, Hippeli, Davis, Elbrecht, Vetere, Nazzari and Mollo. This is an open-access article distributed under the terms of the Creative Commons Attribution License (CC BY). The use, distribution or reproduction in other forums is permitted, provided the original author(s) and the copyright owner(s) are credited and that the original publication in this journal is cited, in accordance with accepted academic practice. No use, distribution or reproduction is permitted which does not comply with these terms. 